\title{
OCCUPATIONAL CLASSIFICATION OF MATHEMATICIANS
}

\section{MEMORANDUM F}

Occupational Bulletins No. 10 and No. 23 have recently been amended by Selective Service Headquarters. These are the directives upon which chairmen of departments of mathematics have been basing requests for the occupational classification of members of their staffs and of students majoring in mathematics.

It is to be noted particularly that, according to both Bulletins, a graduate student in mathematics may be considered for occupational classification only if, in addition to pursuing graduate studies, he is acting as a graduate assistant and is engaged in:

(a) classroom instruction for not less than twelve hours per week; or

(b) scientific research certified by a recognized federal agency as related to the war effort.

The amended Bulletins supersede the original directives. In making requests for occupational classification, chairmen of departments of mathematics are advised to attach copies of the amended Bulletins to Form 42A. Copies of the revised Bulletins will be furnished, upon request, by the office of the Secretary. In all other details, the procedure recommended in Memorandum E, distributed on October 28, 1942, and published in the November, 1942, Bulletin of the American Mathematical Society, remains unchanged.

January 30, 1943

J. R. KLINE, Secretary 